\title{
PODER LEGISLATIVO E MULHERES EM PINHAIS
} $(1993-2016)^{1}$

\author{
Gloria Estevinho ${ }^{2}$ \\ Ana Crhistina Vanali ${ }^{3}$
}

- Enviado em 15/04/2016

- Aprovado em 20/05/2016

\section{RESUMO}

Este artigo tem por objetivo analisar a participação política das mulheres na Câmara Municipal de Pinhais, município da região metropolitana de Curitiba/PR entre os anos de 1993 a 2016. Para tanto, um banco de dados dos candidatos eleitos foi construído e, com ele, foi possível apresentar um balanço da participação das mulheres nas eleições municipais, analisar o perfil das vereadoras a partir de dimensões sociais e econômicas, tais como idade, estado civil, escolaridade, profissão e filiação partidária. Os resultados marcam uma participação feminina muito baixa se comparada com a presença masculina. Em que pese certa abertura e incentivo no sentido de maior participação das mulheres na vida político-partidária, como estabelece a lei de cotas, essa participação está muito aquém do seu contingente populacional, como revelam os dados sobre a participação feminina no poder legislativo local de Pinhais.

Palavras-chave: Mulheres na política. Política e gênero. Câmara Municipal Pinhais.

\section{INTRODUÇÃO}

No último dia 20 de março de 2016 o município de Pinhais comemorou 24 anos tendo sido criado pela Lei № 9.906 de 1992 que foi promulgada pelo presidente da Assembleia Legislativa do Paraná na época, deputado Aníbal Khury. O município nasceu com uma extensão territorial de

\footnotetext{
${ }^{1}$ Uma versão preliminar desse trabalho foi apresentada no GT1: INSTITUIÇÕES E PODER: PARENTESCOS E GENEALOGIAS do VII Seminário Nacional de Sociologia e Política da UFPR realizado de 11 a 13 de maio de 2016 em Curitiba.

${ }^{2}$ Graduada em Ciências Sociais pela Universidade Federal do Paraná. Especialista em Sociologia Política pela UFPR. Endereço eletrônico: estevinho_gomes@ hotmail.com

${ }^{3}$ Doutoranda em Sociologia do Programa de Pós-graduação da UFPR. Endereço eletrônico: anacvanali@ yahoo.com.br
} 
$60,92 \mathrm{~km}^{2}$, quando foi desmembrado do município de Piraquara. Pinhais nasceu das ideias posta no Projeto de Lei $\mathrm{N}^{\circ}$ 271/86 , apresentado pelo então Deputado Estadual Aníbal Khury e inicialmente contemplava apenas $22 \mathrm{~km}$ de extensão. Essa proposta deixava de fora bairros importantes como Maria Antonieta, Jardim Amélia, Alphaville Graciosa, Parque das Nascentes e Parque das Águas e isso provocou uma reação da população e dos partidos políticos. A Proposta de Lei № 9.906/92 nasce em substituição do referido projeto e contempla além dos bairros citados a extensão que vai do rio Atuba e Irai (Antigo Leito) até o encontro com o Rio Canguri na divisa do município de Quatro Barras e continua a nordeste até a PR-410 (Estrada da Graciosa), por esta direção a Oeste segue até chegar ao rio Atuba, a partir de onde segue a Sul, até a confluência do rio Iraí. Segundo Silva (2008, p. 8):

A emancipação de Pinhais não foi um processo isolado: faz parte de um processo mais amplo de desmembramento dos municípios brasileiros, apontado pela literatura como recorrente no país após a promulgação da Constituição de 1988 ... Essa Constituição incentivou os processos emancipatórios municipais, na medida em que exigia a realização de um Plebiscito de consulta à população ligada diretamente à área a ser desmembrada, sem consultar a população do município como um todo. O parágrafo $4^{\circ}$ do artigo de número 18 , do capítulo I - da Organização Político-Administrativo, da Constituição Federal dispõe sobre a criação de novos municípios e estabelece os trâmites legais ...

Os desmembramentos municipais multiplicaram-se no país após a promulgação da Constituição de $1988^{5}$ e no Paraná, o grande articulador político dos processos de emancipação foi o deputado estadual Aníbal Khury, responsável por $15 \%$ da criação de novos municípios no Estado, ganhando a alcunha de "Pai" das cidades que criou.

Pinhais tem a sua história bastante recente, mas a ocupação de seu território remonta há vários séculos quando o Planalto Curitibano começa a ser ocupado no final do século XVI e alguns povoados surgem em decorrência disso. A área de Pinhais pertenceu ao território de Curitiba até fins do século XIX. No ano de 1890, uma parte do território de Curitiba foi desmembrada, passando a constituir o município de Colombo. A região que comportava Pinhais estava inserida nessa área desmembrada, o que significa que Pinhais passou a pertencer, administrativa e politicamente, a

\footnotetext{
${ }^{4}$ Disponível em http://www.alep.pr.gov.br/web/pesquisa_projetos/pesquisa_projetos.php. Acesso em 25.março.2016.

${ }^{5}$ Conforme Tomio (2002), entre 1988 e 2000, foram criados 1.438 novos municípios, isto é, $25 \%$ de todos os municípios existentes atualmente no Brasil.
} 
Colombo. Isso pode ser constatado pelo decreto $\mathrm{N}^{\mathrm{o}} 71$ de 31 de janeiro de $1890^{6}$, que fixou os limites do novo município (SILVA, 2010).

A partir da década de 1930, o Paraná passou a ser administrado pelo interventor Manoel Ribas, que realizou mudanças de cunho político-administrativo, interferindo inclusive na delimitação geográfica de vários municípios do estado. Dentro desse processo, no ano de 1932, o território onde se situa Pinhais passou a pertencer ao município de Piraquara, no mesmo momento em que o município de Colombo foi extinto (seu território foi reanexado ao de Curitiba, sendo recriado mais tarde). O município de Piraquara havia sido desmembrado de São José dos Pinhais na mesma época em que a área de Colombo foi desmembrada de Curitiba. O Decreto $\mathrm{N}^{\mathrm{o}} 2.505$ de 27 de outubro de 1932, fixou os novos limites de Piraquara, anexando o território de Pinhais ${ }^{7}$. Na década de 1960, a comunidade começou a reivindicar a instalação de serviços públicos locais. Paralelamente, começaram a ser eleitos os primeiros representantes pinhaienses que ingressaram na ordem política do município de Piraquara. Devido à importância e a participação que o povoado conquistou no cenário político municipal, Pinhais foi elevado à categoria de Distrito em 21 de novembro de 1964. Nos anos 1970 e 1980, o distrito recebeu um enorme contingente populacional, acarretando demandas em vários setores. Assim, em 1991 foi realizado um plebiscito que revelou um alto índice de aprovação da emancipação política, cerca de 20.456 de um total de 23.310 participantes (87\% de aprovação $)^{8}$ (XAVIER, 2000).

Atendendo a essa solicitação dos moradores do distrito, o deputado estadual Aníbal Khury (então presidente da Assembleia Legislativa do Paraná), determinou a criação do município de Pinhais, sendo o seu território desmembrado do de Piraquara. O município de Pinhais foi oficialmente instalado no dia 20 de março do ano de 1992. Sendo eleito como primeiro prefeito de Pinhais João Batista Costa, que assumiu a prefeitura em 01 de janeiro de 1993. Até o momento, o poder executivo de Pinhais teve os seguintes representantes:

\footnotetext{
${ }^{6}$ Para acesso as leis estaduais consultar site do Arquivo Público do Paraná http://www.arquivopublico.pr.gov.br/. Acesso em 29.fev.2016.

7 Para acesso as leis estaduais consultar site do Arquivo Público do Paraná http://www.arquivopublico.pr.gov.br/. Acesso em 29.fev.2016.

${ }^{8}$ Consultar também http://www.pinhais.pr.gov.br/acidade/FreeComponent16content289.shtml. Acesso em 29.fev.2016. 
QUADRO 1 - PREFEITOS DE PINHAIS DE 1993 ATÉ 2016

\begin{tabular}{|c|c|c|c|c|c|c|}
\hline Nome do Prefeito & Mandato & $\begin{array}{l}\text { Filiação } \\
\text { Partidária }\end{array}$ & $\begin{array}{c}\text { Data de } \\
\text { Nascimento }\end{array}$ & $\begin{array}{l}\text { Grau de } \\
\text { instrução }\end{array}$ & Estado Civil & Ocupação \\
\hline João Batista Costa9 & $\begin{array}{l}01.01 .1993 \\
31.12 .1996\end{array}$ & $\begin{array}{c}\text { PTB } \\
(9.578 \text { votos })\end{array}$ & $10 / 06 / 1947$ & $\begin{array}{l}\text { Fundamental } \\
\text { incompleto }\end{array}$ & Casado & $\begin{array}{l}\text { Servidor } \\
\text { público } \\
\text { municipal }\end{array}$ \\
\hline $\begin{array}{l}\text { Siegfried "Zico" } \\
\text { Böving }\end{array}$ & $\begin{array}{l}01.01 .1997 \\
31.12 .2000\end{array}$ & $\begin{array}{c}\text { PDT } \\
\text { (14.963 votos) }\end{array}$ & $14 / 09 / 1951$ & $\begin{array}{c}\text { Médio } \\
\text { incompleto }\end{array}$ & Casado & Outros \\
\hline $\begin{array}{l}\text { Luiz Cassiano de } \\
\text { Castro Fernandes }\end{array}$ & $\begin{array}{l}01.01 .2001 \\
31.12 .2004 \\
01.01 .2004 \\
30.06 .2006\end{array}$ & $\begin{array}{c}\text { PSDB } \\
\left(1^{\circ} \text { mandato }\right) \\
(23.459 \text { votos }) \\
\text { PRP } \\
\left(2^{\circ} \text { mandato }\right) \\
(22.552 \text { votos })\end{array}$ & $04 / 07 / 1942$ & $\begin{array}{l}\text { Médio } \\
\text { completo }\end{array}$ & Solteiro & Comerciário \\
\hline $\begin{array}{l}\text { Mario Bonaldo } \\
\text { (vice que assumiu) }\end{array}$ & $\begin{array}{l}01.07 .2006 \\
21.12 .2008\end{array}$ & PRP & 03/05/1948 & $\begin{array}{l}\text { Superior } \\
\text { completo }\end{array}$ & Casado & $\begin{array}{c}\text { Administrad } \\
\text { or }\end{array}$ \\
\hline $\begin{array}{l}\text { Luiz Goularte Alves } \\
\text { (Luizão) }^{13}\end{array}$ & $\begin{array}{l}01.01 .2009 \\
31.12 .2012 \\
01.01 .2013\end{array}$ & $\begin{array}{c}\mathrm{PT} \\
\left(1^{\circ} \text { mandato }\right) \\
(39.438 \text { votos }) \\
\left(2^{\circ} \text { mandato }\right) \\
(62.802 \text { votos })\end{array}$ & 06/06/1962 & $\begin{array}{l}\text { Superior } \\
\text { completo }\end{array}$ & Divorciado & Professor \\
\hline
\end{tabular}

Elaboração das autoras. FONTE: Sítio do TRE-PR - http://www.tre-pr.jus.br/. Acesso em 29.fev.2016.

Mesmo sendo o menor dos 399 municípios paranaenses, em área territorial, com 60,92 km², Pinhais figura entre as 14 cidades mais populosas do estado, com uma população de 117.008 habitantes ${ }^{14}$. No município, distante $10 \mathrm{~km}$ de Curitiba, está localizado o Autódromo Internacional de Curitiba, o Expotrade (um dos maiores Centros de Convenções e Exposições do estado),

\footnotetext{
${ }^{9}$ Dados extraídos do sítio https://tre-pr.jus.br/. Acesso em 24.março.2016.

${ }^{10}$ Dados extraídos do sítio https://apps.tre-pr.jus.br/files/resultados/19961003A75043.pdf. Acesso em 24.março.2016.

${ }^{11}$ Dados extraídos do sítio https://apps.tre-pr.jus.br/files/resultados/. Acesso em 24.março.2016. Deixa cargo de prefeito para concorrer às eleições de 2006 para deputado estadual pelo PMDB, mas não foi eleito

${ }^{12}$ Dados extraídos do sítio https://apps.tre-pr.jus.br/files/resultados/. Acesso em 24.março.2016.

${ }^{13}$ Dados extraídos do sítio https://apps.tre-pr.jus.br/files/resultados/20081005A75043.pdf. Acesso em 24.março.2016.

${ }^{14}$ Disponível em http://cidades.ibge.gov.br/painel/painel.php?codmun=411915. Acesso 24.março.2016.
} 
a Granja do Canguiri (residência oficial do governador do Paraná) e grandes condomínios horizontais, dentre os quais destacam-se o complexo Pineville e os loteamentos Alphaville Graciosa e Alphaville Pinheiros, ambos às margens da centenária Estrada da Graciosa. O número de eleitores registrados no município é de $89.285^{15}$.

\section{QUADRO 2 - INDICADORES ECONÔMICOS DE PINHAIS}

\begin{tabular}{|c|c|}
\hline \multicolumn{2}{|c|}{ Indicadores Econômicos de Pinhais } \\
\hline$\underline{\text { IDH }}$ & 0,815 \\
\hline$\underline{\text { PIB }}$ & $\mathrm{R} \$ 4.493 .030,41 \mathrm{mil}$ \\
\hline$\underline{\text { PIB per capita }}$ & $\mathrm{R} \$ 38.347,56$ \\
\hline Densidade Demográfica & $1.913,48$ habitantes $/ \mathrm{km}^{2}$ \\
\hline Taxa de pobreza & $14,18 \%$ \\
\hline
\end{tabular}

Fonte: Paraná em números.

Disponível http://www.ipardes.gov.br/index.php?pg_conteudo=1\&cod_conteudo=1. Acesso 24.março. 2016

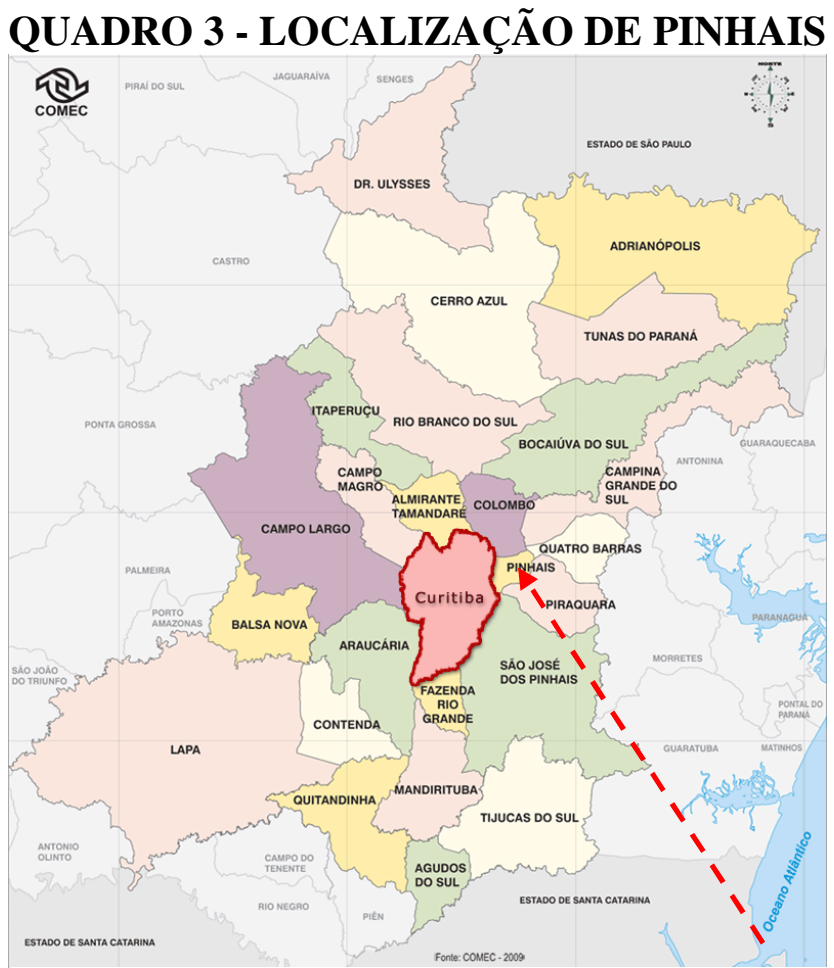

Fonte: Paraná. Pinhais - infográficos: dados gerais do município. Disponível em http://cod.ibge.gov.br/M47. Acesso 24.março.2016

\footnotetext{
${ }^{15}$ Conforme http://www.tse.jus.br/eleitores/eleitores-paraná/pinhais. Acesso em 29.fev.2016.
} 


\section{O PODER LEGISLATIVO EM PINHAIS}

Pinhais foi um dos 42 municípios criados no Paraná em 1992 pelo deputado Aníbal Khury ${ }^{16}$. Silva (2008) nos relata que o processo de emancipação não foi tranquilo pois enfrentou a oposição do governador do Estado na época, Roberto Requião que entrou na justiça para impedir a criação de novos municípios, mas, apesar da confusão política a ALEP deu continuidade ao processo conforme as exigências legais. ${ }^{17}$ Isso evidencia mais uma prática do CURISMO, conforme aponta Oliveira (2001 e 2012) pois Aníbal Khury se tornava o padrinho desses novos municípios e assim perpetuava seu nome como figura de legitimidade pela população para representar a população de Pinhais (e dos outros municípios criados) na ALEP. Com a criação dos municípios eram criados "currais eleitorais", a base de votos de Khury era ampliada pois ele conseguia a simpatia tanto dos moradores como dos políticos locais, garantindo assim as suas sucessivas reeleições e a de seu sucessor, o neto Alexandre Khury.

A Câmara Municipal de Pinhais foi instalada em 1993. Inicialmente funcionou no edifício onde hoje está a SANEPAR na Avenida Camilo de Léllis, 238. Depois passou para o local onde hoje se encontra a sede da Igreja Universal Reino de Deus na Avenida Camilo de Léllis, 476. Desde 2002 ocupa as instalações atuais na Avenida Camilo de Léllis, 393.

A primeira legislatura (1993-1996) foi composta de 15 vereadores. A segunda (1997-2000) e a terceira (2001-2004) legislaturas foram composta de 17 vereadores cada. Às vésperas da $4^{\mathrm{a}}$ legislatura (2005-2008) foi votada a redução do número de vereadores para se adaptar a legislação vigente e a Câmara Municipal de Pinhais (CMP) passou a contar com 11 vereadores. A $5^{\mathrm{a}}$ legislatura (2009-2012) também contou com 11 vereadores. Na legislatura atual, a 6 a (2013-2016), a Câmara Municipal de Pinhais conta com 15 vereadores.

\footnotetext{
${ }^{16}$ Entre os outros podemos destacar Umuarama, Carambeí, Fazenda Rio Grande, Pontal do Paraná, Doutor Ulisses, Tunas do Paraná, Itaperuçu, Jussara, Cianorte, Formosa do Oeste, Altônia, Goioerê, Iracema do Oeste, Cafezal do Sul, etc. IN: Paraná perde o Senhor das urnas. Revista Divulgação Paraná, Curitiba, Ano IX, N.106, Setembro de 1999.

${ }^{17}$ Silva (2008) também destaca as notícias da imprensa da época da emancipação que alertavam que Pinhais ameaçava Piraquara que com a emancipação do distrito perdeu 65 mil habitantes, ficando com 30 mil, além dos estabelecimentos comerciais e industriais que resultou numa queda brusca de arrecadação.
} 


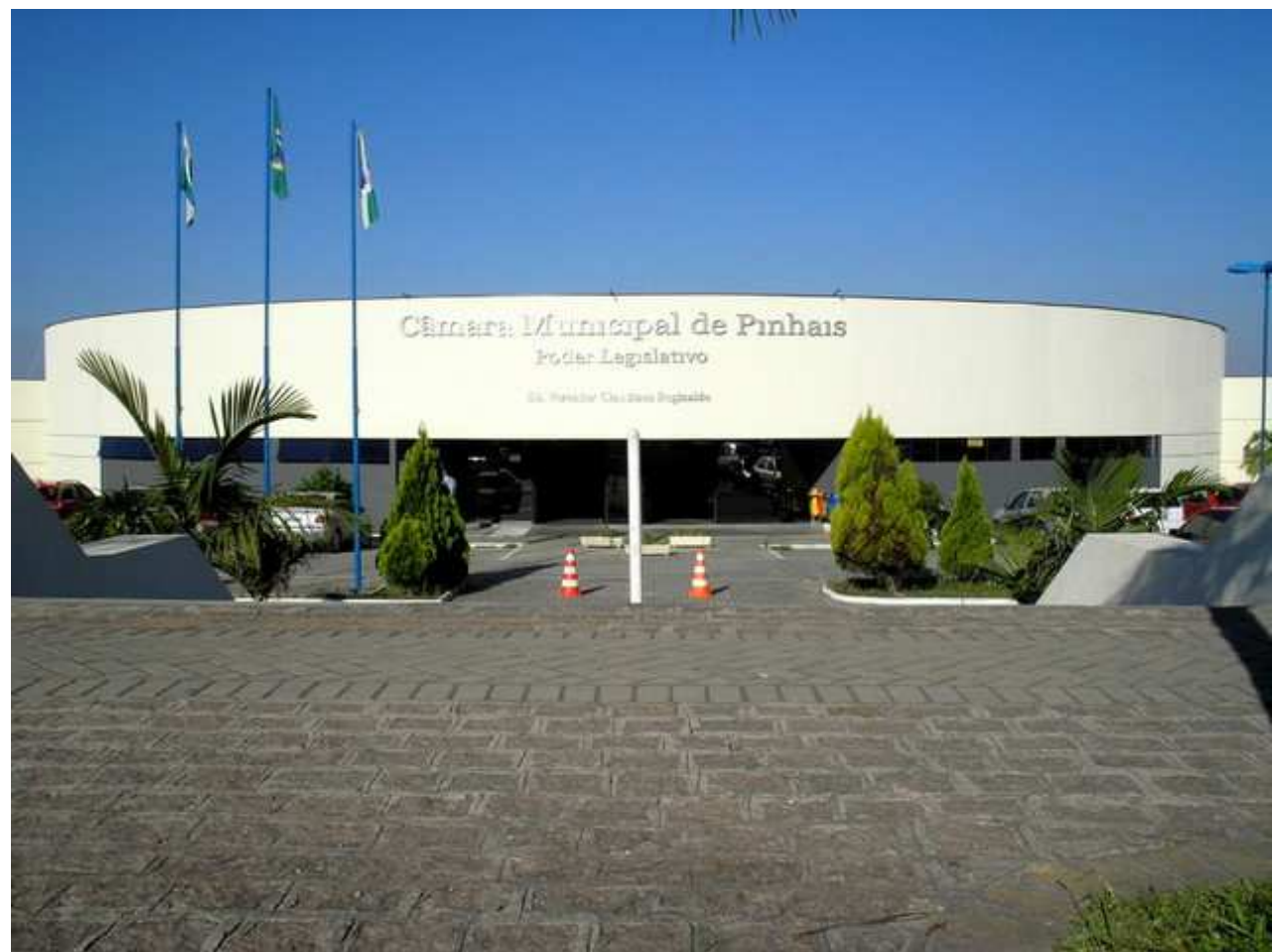

Fonte: http://www.bocamaldita.com/tag/camara-municipal/. Acesso 25.março.2016

A seguir fornecemos o levantamento dos parlamentares que compuseram as diferentes legislaturas da Câmara Municipal de Pinhais desde a sua implantação até a legislatura atual. 


\section{$1^{\text {a }}$ Legislatura 1993-1996}

\section{$1^{\circ}$ BIÊNIO}

Presidente: Vinicius da Cruz

Vice-Presidente: Leonildo Sandri

$1^{\circ}$ Secretário: Sergio Luiz de Souza

$2^{\circ}$ Secretário: Lineu Pires

\section{$2^{\circ}$ BIÊNIO}

Presidente: Gilmar Jorge Batista dos Santos

Vice-Presidente: Edelmir Duarte

$1^{\circ}$ Secretário: Marcos Chescin

$\mathbf{2}^{\mathbf{o}}$ Secretário: Pedro Miguel da Silva

\begin{tabular}{|c|c|c|c|c|c|c|c|}
\hline \multicolumn{2}{|r|}{ Vereadores } & Filiação & Qtde & Data & Est. Civil & Escolaridade & Profissão \\
\hline 1 & $\begin{array}{l}\text { Aylton Ferreira de } \\
\text { Lima }\end{array}$ & PFL & 332 & $13 / 04 / 1958$ & Divorciado & $\begin{array}{l}\text { Ensino médio } \\
\text { incompleto }\end{array}$ & Comerciante \\
\hline 2 & Edelmir Duarte & PDT & 394 & 19/08/1954 & Solteiro & Ensino médio & Empresário \\
\hline 3 & $\begin{array}{l}\text { Gilmar Jorge Batista } \\
\text { dos Santos }\end{array}$ & PST & 453 & $14 / 12 / 1957$ & Solteiro & Superior completo & Comerciante \\
\hline 4 & João de Souza & PMDB & 425 & $05 / 06 / 1959$ & Casado & Ensino médio & Comerciante \\
\hline 5 & $\begin{array}{l}\text { Jucelino } \quad \text { Batista } \\
\text { Liduario }\end{array}$ & PTB & 394 & $21 / 04 / 1960$ & Casado & $\begin{array}{c}\text { Ensino } \\
\text { fundamental }\end{array}$ & Outros \\
\hline 6 & Leonildo Sandri & PDT & 328 & $10 / 01 / 1955$ & Casado & $\begin{array}{c}\text { Ensino } \\
\text { fundamental }\end{array}$ & Empresário \\
\hline 7 & Lineu Pires & PDT & 301 & 19/01/1961 & Casado & Ensino médio & Comerciante \\
\hline 8 & Luiz Cipriani & PTB & 447 & & & & \\
\hline 9 & Marcos Ceschin & PST & 410 & $25 / 07 / 1955$ & Casado & Superior completo & Médico \\
\hline 10 & $\begin{array}{ll}\text { Pedro } & \text { Esmério } \\
\text { Pereira } & \end{array}$ & PFL & 372 & $16 / 02 / 1959$ & Casado & $\begin{array}{l}\text { Ensino médio } \\
\text { incompleto }\end{array}$ & Comerciante \\
\hline 11 & $\begin{array}{lll}\text { Pedro } & \text { Miguel } & \text { da } \\
\text { Silva } & & \\
\end{array}$ & PST & 323 & $15 / 10 / 1946$ & Casado & $\begin{array}{c}\text { Ensino } \\
\text { fundamental }\end{array}$ & $\begin{array}{c}\text { Aposentado } \\
\text { serviço } \\
\text { público }\end{array}$ \\
\hline 12 & Rubens Kirstein & PTB & 490 & $17 / 11 / 1937$ & & & \\
\hline 13 & Sergio Luiz de Souza & PTB & 589 & $02 / 03 / 1965$ & Casado & Superior completo & Engenheiro \\
\hline 14 & Tulio Telmo Cagliari & PTB & 480 & $09 / 09 / 1952$ & Casado & Superior completo & Médico \\
\hline 15 & Vinícius da Cruz & PTB & 536 & $01 / 08 / 1952$ & Casado & Ensino médio & Outros \\
\hline & $\begin{array}{l}\text { Vicente de Souza - } \\
\text { SUPLENTE }\end{array}$ & PTB & 275 & $30 / 08 / 1956$ & Casado & $\begin{array}{c}\text { Ensino } \\
\text { fundamental } \\
\text { incompleto }\end{array}$ & Empresário \\
\hline
\end{tabular}

Elaboração das autoras

FONTE: http://www.cmp.pr.gov.br/ e https://apps.tre-pr.jus.br/files/resultados/19921003A75043.pdf (Justiça Eleitoral - Eleições Municipais de 03 de outubro de 1992). Acesso 29.fev.2016 


\section{$2^{a}$ Legislatura 1997-2000}

\section{$1^{\circ}$ BIÊNIO}

Presidente: João de Souza

Vice-Presidente: Luiz Goularte Alves

$1^{\text {a }}$ Secretária: Marly Paulino Fagundes

$2^{\circ}$ Secretário: Marcos Ceschin

\section{$2^{\circ}$ BIÊNIO}

Presidente: Lineu Pires

Vice-Presidente: Pedro Miguel da Silva

$1^{\circ}$ Secretário: Édio Paulo de Souza

$2^{\mathbf{o}}$ Secretário: Aylton Ferreira de Lima

\begin{tabular}{|c|c|c|c|c|c|c|c|}
\hline \multicolumn{2}{|r|}{ Vereadores } & Filiação & Qtde & Data & Est. Civil & Escolaridade & Profissão \\
\hline 1 & Aylton Ferreira de Lima & PDT & 912 & $13 / 04 / 1958$ & Divorciado & Médio incompleto & Comerciante \\
\hline 2 & Édio Paulo de Souza & PSC & 426 & $17 / 09 / 1961$ & Casado & Ensino médio & Vendedor \\
\hline 3 & Geso Soares de Oliveira & PSDB & 447 & $16 / 11 / 1956$ & Divorciado & Ensino médio & Outros \\
\hline 4 & $\begin{array}{l}\text { Gilmar Jorge Batista dos } \\
\text { Santos }\end{array}$ & PPB & 789 & $14 / 12 / 1957$ & Solteiro & $\begin{array}{l}\text { Superior } \\
\text { completo }\end{array}$ & Comerciante \\
\hline 5 & João de Souza & PMDB & 513 & $05 / 06 / 1959$ & Casado & Ensino médio & Comerciante \\
\hline 6 & José Rodrigues Dias & PSDB & 526 & $22 / 07 / 1953$ & Casado & $\begin{array}{l}\text { Fundamental } \\
\text { incompleto }\end{array}$ & Comerciante \\
\hline 7 & Lineu Pires & PDT & 643 & $19 / 01 / 1961$ & Casado & Ensino médio & Comerciante \\
\hline 8 & Luiz Goularte Alves & PT & 670 & $06 / 06 / 1962$ & Divorciado & Superior completo & Professor \\
\hline 9 & Marcos Ceschin & PSDB & 619 & $25 / 07 / 1955$ & Casado & Superior completo & Médico \\
\hline 10 & $\begin{array}{ll}\text { Marly } & \text { Paulino } \\
\text { Fagundes }^{18} & \end{array}$ & PSC & 336 & $07 / 04 / 1965$ & Viúva & Ensino médio & $\begin{array}{c}\text { Agente } \\
\text { administrativo }\end{array}$ \\
\hline 11 & Osmar Nunes Cardoso & PDT & 515 & $09 / 10 / 1951$ & Casado & $\begin{array}{l}\text { Fundamental } \\
\text { incompleto }\end{array}$ & $\begin{array}{c}\text { Não } \\
\text { localizado }\end{array}$ \\
\hline 12 & Paulo Pereira da Silva & PMDB & 612 & $01 / 05 / 1962$ & Casado & Ensino médio & Motorista \\
\hline 13 & Pedro Miguel da Silva & PTB & 524 & $15 / 10 / 1946$ & Casado & $\begin{array}{c}\text { Ensino } \\
\text { fundamental }\end{array}$ & $\begin{array}{c}\text { Aposentado } \\
\text { serviço } \\
\text { público }\end{array}$ \\
\hline 14 & $\begin{array}{l}\text { Sebastião Carlos dos } \\
\text { Santos }\end{array}$ & PT & 236 & $25 / 04 / 1954$ & Casado & $\begin{array}{l}\text { Ensino } \\
\text { Superior }\end{array}$ & Outros \\
\hline 15 & Sergio Luiz de Souza & PTB & 694 & $02 / 03 / 1965$ & Casado & Superior completo & Engenheiro \\
\hline 16 & Vicente de Souza & PTB & 567 & $30 / 08 / 1956$ & Casado & $\begin{array}{l}\text { Fundamental } \\
\text { incompleto }\end{array}$ & Empresário \\
\hline 17 & Vinícius da Cruz & PPB & 499 & $01 / 08 / 1952$ & Casado & Ensino médio & Outros \\
\hline & $\begin{array}{l}\text { José Hamilton Ribeiro - } \\
\text { SUPLENTE }^{19}\end{array}$ & PSDB & 404 & $18 / 07 / 1952$ & Casado & Médio incompleto & Outros \\
\hline & $\begin{array}{lr}\text { Jucelino } & \text { Batista } \\
\text { Liduário - SUPLENTE } & \end{array}$ & PTB & 419 & $21 / 04 / 1960$ & Casado & Fundamental & Outros \\
\hline
\end{tabular}

Elaboração das autoras

FONTE: http://www.cmp.pr.gov.br/ e https://apps.tre-pr.jus.br/files/resultados/19921003A75043.pdf (Justiça Eleitoral - Eleições $\begin{array}{lllll}\text { Municipais de } & \text { outubro } & \text { de } & \text { 1996). } & \text { Acesso }\end{array}$

\footnotetext{
${ }^{18}$ Primeira vereadora eleita no município de Pinhais.

19 José Hamilton Ribeiro: suplente que assumiu a vaga de Marcos Ceschin que foi para a Secretaria Municipal da Saúde.

${ }^{20}$ Jucelino Batista Liduário: suplente que assumiu a vaga de Sérgio Luiz de Souza que foi para a Secretaria Municipal de Obras.
} 


\section{$3^{\text {a }}$ Legislatura 2001-2004}

$1^{\circ}$ BIÊNIO

Presidente: Luiz Goularte Alves

Vice-Presidente: Osmar Nunes Cardoso

$\mathbf{1}^{\circ}$ Secretário: Vinicius da Cruz

$2^{\circ}$ Secretário: João de Souza

\section{$2^{\circ}$ BIÊNIO}

Presidente: Osmar Nunes Cardoso

Vice-Presidente: Sergio Luiz de Souza

$1^{\circ}$ Secretário: José Hamilton Ribeiro

$2^{\circ}$ Secretária: Rita de Cassia Cruz Romaniow

\begin{tabular}{|c|c|c|c|c|c|c|c|}
\hline \multicolumn{2}{|r|}{ Vereadores } & Filiação & Qtde & Data & Est. Civil & Escolaridade & Profissão \\
\hline 1 & Agilson Ferreira de Lima & PSB & 882 & $15 / 10 / 1969$ & Casado & Ensino médio & Comerciante \\
\hline 2 & Claudinez Reginaldo & PFL & 778 & $11 / 01 / 1961$ & Casado & $\begin{array}{l}\text { Ensino médio } \\
\text { incompleto }\end{array}$ & Outros \\
\hline 3 & Egon Wilhems & PT & 717 & $12 / 05 / 1958$ & Casado & $\begin{array}{l}\text { Superior } \\
\text { completo }\end{array}$ & Professor \\
\hline 4 & Flazio Gorges & PSDB & 684 & $02 / 03 / 1953$ & Casado & $\begin{array}{l}\text { Superior } \\
\text { completo }\end{array}$ & Comerciante \\
\hline 5 & Geso Soares de Oliveira & PFL & 829 & $16 / 11 / 1956$ & Divorciado & Ensino médio & Outros \\
\hline 6 & Jean Alexandre dos Santos & PSDB & 709 & $02 / 03 / 1973$ & $\begin{array}{c}\text { Não } \\
\text { informado }\end{array}$ & Ensino médio & Comerciante \\
\hline 7 & João de Souza & PMDB & 587 & $05 / 06 / 1959$ & Casado & Ensino médio & Comerciante \\
\hline 8 & José Hamilton Ribeiro & PFL & 978 & 18/07/1952 & Casado & $\begin{array}{l}\text { Ensino médio } \\
\text { incompleto }\end{array}$ & Outros \\
\hline 9 & José Rodrigues Dias & PMDB & 1047 & $22 / 07 / 1953$ & Casado & $\begin{array}{c}\text { Ensino } \\
\text { fundamental } \\
\text { incompleto }\end{array}$ & Comerciante \\
\hline 10 & Lineu Pires & PTN & 901 & $19 / 01 / 1961$ & Casado & Ensino médio & Comerciante \\
\hline 11 & Luiz Goularte Alves & PT & 1000 & $06 / 06 / 1962$ & Divorciado & $\begin{array}{l}\text { Superior } \\
\text { completo }\end{array}$ & Professor \\
\hline 12 & Marcos Ceschin & PFL & 1009 & $25 / 07 / 1955$ & Casado & $\begin{array}{l}\text { Superior } \\
\text { completo }\end{array}$ & Médico \\
\hline 13 & Marly Paulino Fagundes & PMDB & 810 & $07 / 04 / 1965$ & Viúva & Ensino médio & $\begin{array}{c}\text { Agente } \\
\text { administrativo }\end{array}$ \\
\hline 14 & $\begin{array}{l}\text { Rita de Cassia Cruz } \\
\text { Romaniow }\end{array}$ & PSB & 561 & 09/09/1962 & Casado & $\begin{array}{l}\text { Superior } \\
\text { completo }\end{array}$ & Médica \\
\hline 15 & Osmar Nunes Cardoso & PDT & 726 & 09/10/1951 & Casado & $\begin{array}{c}\text { Ensino } \\
\text { fundamental } \\
\text { incompleto }\end{array}$ & $\begin{array}{c}\text { Não } \\
\text { localizado }\end{array}$ \\
\hline 16 & Sergio Luiz de Souza & PTB & 1160 & $02 / 03 / 1965$ & Casado & $\begin{array}{l}\text { Ensino } \\
\text { Superior }\end{array}$ & Engenheiro \\
\hline 17 & Vinícius da Cruz & PSDB & 800 & $01 / 08 / 1952$ & Casado & Ensino médio & Outros \\
\hline
\end{tabular}

Elaboração das autoras

FONTE: http://www.cmp.pr.gov.br/ e https://apps.tre-pr.jus.br/files/resultados/19921003A75043.pdf (Justiça Eleitoral - Eleições Municipais de outubro de 2000). Acesso 29.fev.2016 


\section{$4^{\mathrm{a}}$ Legislatura 2005-2008}

$1^{\circ}$ BIÊNIO

Presidente: José Rodrigues Dias

Vice-Presidente: Osmar Nunes Cardoso

$1^{\circ}$ Secretário: Demétrio Cesar Tonon

$2^{\mathbf{0}}$ Secretário: Flázio Gorges

$2^{\circ}$ BIÊNIO

Presidente: Osmar Nunes Cardoso

Vice-Presidente: Flázio Gorges

$1^{a}$ Secretária: Marly Paulino Fernandes

$\mathbf{2}^{\circ}$ Secretário: Agilson Ferreira de Lima

\begin{tabular}{|c|c|c|c|c|c|c|c|}
\hline \multicolumn{2}{|r|}{ Vereadores } & Filiação & Qtde & Data & Est. Civil & Escolaridade & Profissão \\
\hline 1 & Adão Alves de Lima & PP & 1634 & $11 / 07 / 1953$ & Casado & $\begin{array}{l}\text { Ensino médio } \\
\text { incompleto }\end{array}$ & Locutor de rádio \\
\hline 2 & $\begin{array}{l}\text { Agilson Ferreira de } \\
\text { Lima }\end{array}$ & PPS & 1933 & $15 / 10 / 1969$ & Casado & Ensino médio & Comerciante \\
\hline 3 & $\begin{array}{l}\text { Aylton Ferreira de } \\
\text { Lima }\end{array}$ & PTB & 1640 & 13/04/1958 & Divorciado & $\begin{array}{l}\text { Ensino médio } \\
\text { incompleto }\end{array}$ & Comerciante \\
\hline 4 & $\begin{array}{l}\text { Demétrio Cesar } \\
\text { Tonon }\end{array}$ & PP & 1608 & 28/06/1967 & Casado & $\begin{array}{l}\text { Superior } \\
\text { completo }\end{array}$ & Advogado \\
\hline 5 & $\begin{array}{l}\text { Ivone Carvalho dos } \\
\text { Santos }\end{array}$ & PT & 1096 & 27/04/1968 & Solteira & $\begin{array}{l}\text { Ensino médio } \\
\text { completo }\end{array}$ & $\begin{array}{c}\text { Secretario, } \\
\text { Estenografo, } \\
\text { Datilografo, } \\
\text { Recepcionista, } \\
\text { Telefonista, Etc }\end{array}$ \\
\hline 6 & Flazio Gorges & PPS & 1310 & $02 / 03 / 1953$ & Casado & $\begin{array}{l}\text { Superior } \\
\text { completo }\end{array}$ & Comerciante \\
\hline 7 & João Carlos Ribeiro & PT & 1217 & $13 / 07 / 1976$ & Casado & $\begin{array}{c}\text { Ensino } \\
\text { fundamental }\end{array}$ & $\begin{array}{l}\text { Operador De } \\
\text { Equipamento } \\
\text { De Rádio, } \\
\text { Televisão, Som } \\
\text { E Cinema }\end{array}$ \\
\hline 8 & José Rodrigues Dias & PMDB & 1900 & $22 / 07 / 1953$ & Casado & $\begin{array}{c}\text { Ensino } \\
\text { fundamental } \\
\text { incompleto }\end{array}$ & Comerciante \\
\hline 9 & $\begin{array}{l}\text { Mario Marques } \\
\text { Guimarães Neto }\end{array}$ & PFL & 1188 & 26/08/1976 & Casado & Ensino médio & Motorista \\
\hline 10 & $\begin{array}{ll}\text { Marly } & \text { Paulino } \\
\text { Fagundes }^{21} & \end{array}$ & PMDB & 1483 & $07 / 04 / 1965$ & Viúva & Ensino médio & $\begin{array}{c}\text { Agente } \\
\text { administrativo }\end{array}$ \\
\hline 11 & $\begin{array}{ll}\text { Osmar } & \text { Nunes } \\
\text { Cardoso } & \end{array}$ & PDT & 817 & 09/10/1951 & Casado & $\begin{array}{l}\text { Ensino } \\
\text { fundamental } \\
\text { incompleto }\end{array}$ & $\begin{array}{l}\text { Não localizado } \\
\text { antes de ser } \\
\text { vereador }\end{array}$ \\
\hline
\end{tabular}

Elaboração das autoras

FONTE: http://www.cmp.pr.gov.br/ e https://apps.tre-pr.jus.br/files/resultados/19921003A75043.pdf (Justiça Eleitoral - Eleições Municipais de outubro de 2004). Acesso 29.fev.2016

${ }^{21}$ Marly Paulino Fagundes não concorre para a $5^{\circ}$ legislatura como vereadora pois disputou as eleições de outubro de 2008 como vice-prefeita na chapa do Professor Luizão, sendo eleita. 


\section{$5^{\mathrm{a}}$ Legislatura 2009-2012}

$1^{\circ}$ BIÊNIO

Presidente: Demétrio Cesar Tonon

Vice-Presidente: Gilberto Hartkopf

$1^{a}$ Secretária: Ivone Carvalho dos Santos

$2^{\circ}$ Secretário: Adilson Mario da Silva

\section{$2^{\circ}$ BIÊNIO}

Presidente: Ivone Carvalho dos Santos

Vice-Presidente: José Francisco de Souza

$1^{\circ}$ Secretário: Adilson Mario da Silva

$2^{\circ}$ Secretário: Demétrio Cesar Tonon

\begin{tabular}{|c|c|c|c|c|c|c|c|}
\hline \multicolumn{2}{|r|}{ Vereadores } & Filiação & Qtde & Data & Est. & Escolaridade & Profissão \\
\hline 1 & Adilson Mario da Silva & PTB & 1260 & $20 / 06 / 1968$ & Casado & Ensino médio & Administrador \\
\hline 2 & Agilson Ferreira de Lima & PPS & 2092 & $15 / 10 / 1969$ & Casado & Ensino médio & Comerciante \\
\hline 3 & Demétrio Cesar Tonon & $\mathrm{PP}$ & 907 & 28/06/1967 & Casado & $\begin{array}{l}\text { Superior } \\
\text { completo }\end{array}$ & Advogado \\
\hline 4 & Gilberto Hartkopf & PT & 863 & $10 / 03 / 1969$ & Casado & Ensino médio & Comerciante \\
\hline 5 & $\begin{array}{lll}\text { Ivone } & \text { Carvalho dos } \\
\text { Santos }^{22} & & \end{array}$ & PT & 864 & $27 / 04 / 1968$ & Solteira & $\begin{array}{l}\text { Ensino médio } \\
\text { completo }\end{array}$ & $\begin{array}{c}\text { Secretária, } \\
\text { Estenografa, } \\
\text { Datilografa, } \\
\text { Recepcionista, } \\
\text { Telefonista, } \\
\text { Etc } \\
\end{array}$ \\
\hline 6 & José Francisco de Souza & PMDB & 1033 & $04 / 03 / 1956$ & Casado & $\begin{array}{l}\text { Ensino médio } \\
\text { incompleto }\end{array}$ & Comerciante \\
\hline 7 & José Rodrigues Dias & PMDB & 1134 & $22 / 07 / 1953$ & Casado & $\begin{array}{c}\text { Ensino } \\
\text { fundamental } \\
\text { incompleto }\end{array}$ & Comerciante \\
\hline 8 & $\begin{array}{l}\text { Mario } \\
\text { Guimarães Neto }\end{array}$ & PSC & 1301 & $26 / 08 / 1976$ & Casado & Ensino médio & Motorista \\
\hline 9 & Paulo Luciano Ferreira & PP & 1034 & $18 / 11 / 1958$ & Casado & $\begin{array}{c}\text { Ensino } \\
\text { fundamental }\end{array}$ & Empresário \\
\hline 10 & Philipp Markus Gisler & PT & 849 & $07 / 07 / 1959$ & Casado & $\begin{array}{l}\text { Superior } \\
\text { completo }\end{array}$ & Médico \\
\hline 11 & Silvio Aparecido Lindes & PPS & 1466 & $01 / 07 / 1967$ & Casado & $\begin{array}{l}\text { Superior } \\
\text { completo }\end{array}$ & Comerciante \\
\hline
\end{tabular}

Elaboração das autoras

FONTE: http://www.cmp.pr.gov.br/ e https://apps.tre-pr.jus.br/files/resultados/19921003A75043.pdf (Justiça Eleitoral - Eleições Municipais de outubro de 2008). Acesso 29.fev.2016

\footnotetext{
${ }^{22}$ Ivone Carvalho dos Santos foi a primeira mulher presidente da Câmara. Não se reelegeu para a $6^{\mathrm{a}}$ legislatura.
} 


\section{$6^{\text {a }}$ Legislatura 2013-2016}

\section{$1^{\circ}$ BIÊNIO}

Presidente: Gilberto Hartkopf

$\mathbf{1}^{\mathbf{0}}$ Vice-Presidente: Silvio Aparecido Lindes

$2^{\circ}$ Vice-Presidente: Airton Ferreira da Silva

$\mathbf{1}^{\text {a }}$ Secretária: Marcia Regina Ferreira da Silva

$2^{\circ}$ Secretário: Demétrio Cesar Tonon

\begin{tabular}{|c|c|c|c|c|c|c|c|}
\hline \multicolumn{2}{|r|}{ Vereadores } & \multirow{2}{*}{$\begin{array}{c}\begin{array}{c}\text { Filiação } \\
\text { Partidária }\end{array} \\
\text { PPS }\end{array}$} & \multirow{2}{*}{$\begin{array}{l}\text { Qtde } \\
\text { votos } \\
1698\end{array}$} & \multirow{2}{*}{$\begin{array}{c}\begin{array}{c}\text { Data } \\
\text { Nascimento }\end{array} \\
15 / 10 / 1969\end{array}$} & \multirow{2}{*}{$\begin{array}{c}\text { Est. Civil } \\
\text { Casado }\end{array}$} & \multirow{2}{*}{$\begin{array}{l}\text { Escolaridade } \\
\text { Ensino médio }\end{array}$} & \multirow{2}{*}{$\begin{array}{c}\text { Profissão } \\
\text { Comerciante }\end{array}$} \\
\hline 1 & Agilson Ferreira de Lima & & & & & & \\
\hline 2 & Airton Ferreira da Silva & PSC & 772 & $25 / 02 / 1963$ & Casado & Superior & Administrador \\
\hline 3 & $\begin{array}{l}\text { Ari Valdir do Nascimento } \\
\text { Lopes }\end{array}$ & PSDC & 789 & $16 / 12 / 1961$ & Casado & $\begin{array}{c}\text { Ensino } \\
\text { fundamental }\end{array}$ & Empresário \\
\hline 4 & Cecilia Padovan Serafin & PDT & 754 & 29/11/1945 & Casada & $\begin{array}{c}\text { Ensino } \\
\text { fundamental }\end{array}$ & $\begin{array}{l}\text { Servidora } \\
\text { pública }\end{array}$ \\
\hline 5 & Demétrio Cesar Tonon & PP & 961 & 28/06/1967 & Casado & $\begin{array}{l}\text { Superior } \\
\text { completo }\end{array}$ & Advogado \\
\hline 6 & Gilberto Hartkopf & PT & 1159 & $10 / 03 / 1969$ & Casado & Ensino médio & Comerciante \\
\hline 7 & João Carlos Ribeiro & PSB & 1177 & $13 / 07 / 1976$ & Casado & $\begin{array}{c}\text { Ensino } \\
\text { fundamental }\end{array}$ & $\begin{array}{l}\text { Operador De } \\
\text { Equipamento } \\
\text { De Rádio, } \\
\text { Televisão, Som } \\
\text { E Cinema }\end{array}$ \\
\hline 8 & José Rodrigues Dias & PMDB & 988 & $22 / 07 / 1953$ & Casado & $\begin{array}{c}\text { Ensino } \\
\text { fundamental } \\
\text { incompleto }\end{array}$ & Comerciante \\
\hline 9 & Leonildo Sandri & PRB & 1085 & $10 / 01 / 1955$ & Casado & $\begin{array}{c}\text { Ensino } \\
\text { fundamental }\end{array}$ & Empresário \\
\hline 10 & $\begin{array}{l}\text { Marcia Regina Ferreira da } \\
\text { Silva }\end{array}$ & PMDB & 982 & $17 / 07 / 1974$ & Casada & $\begin{array}{l}\text { Superior } \\
\text { completo }\end{array}$ & Socióloga \\
\hline 11 & $\begin{array}{l}\text { Maria Janeide de Souza } \\
\text { Piacentini }\end{array}$ & PR & 1107 & $25 / 03 / 1967$ & Casada & Ensino médio & Outros \\
\hline 12 & Oswaldo Tolentino da Silva & PT & 1107 & $16 / 03 / 1955$ & Casado & $\begin{array}{c}\text { Ensino } \\
\text { fundamental }\end{array}$ & $\begin{array}{l}\text { Trabalhador da } \\
\text { construção civil }\end{array}$ \\
\hline 13 & Otavio Leodoro dos Santos & PT & 1109 & $19 / 03 / 1951$ & Casado & Ensino médio & Empresário \\
\hline 14 & $\begin{array}{l}\text { Rosa Maria de } \\
\text { Colombo }\end{array}$ & PT & 1437 & $17 / 09 / 1965$ & Casada & $\begin{array}{l}\text { Superior } \\
\text { completo }\end{array}$ & Professora \\
\hline 15 & Silvio Aparecido Lindes & PPS & 1201 & 01/07/1967 & Casado & $\begin{array}{l}\text { Superior } \\
\text { completo }\end{array}$ & Comerciante \\
\hline & $\begin{array}{l}\text { Carlos Pereira Borges da } \\
\text { Rosa }^{23} \text { - SUPLENTE }\end{array}$ & PT & 1054 & $07 / 08 / 1980$ & Casado & Ensino médio & $\begin{array}{c}\text { Gerente } \\
\text { estabelecimento } \\
\text { comercial }\end{array}$ \\
\hline
\end{tabular}

Elaboração das autoras

FONTE: http://www.cmp.pr.gov.br/ e https://apps.tre-pr.jus.br/files/resultados/19921003A75043.pdf (Justiça Eleitoral - Eleições Municipais de outubro de 2012). Acesso 29.fev.2016

${ }^{23}$ Carlos Pereira Borges da Rosa: suplente que assumiu a vaga de Rosa Maria que foi para a Secretaria Municipal de Administração. 


\section{AS MULHERES NO PODER LEGISLATIVO DE PINHAIS}

\section{MARLY PAULINO FAGUNDES}

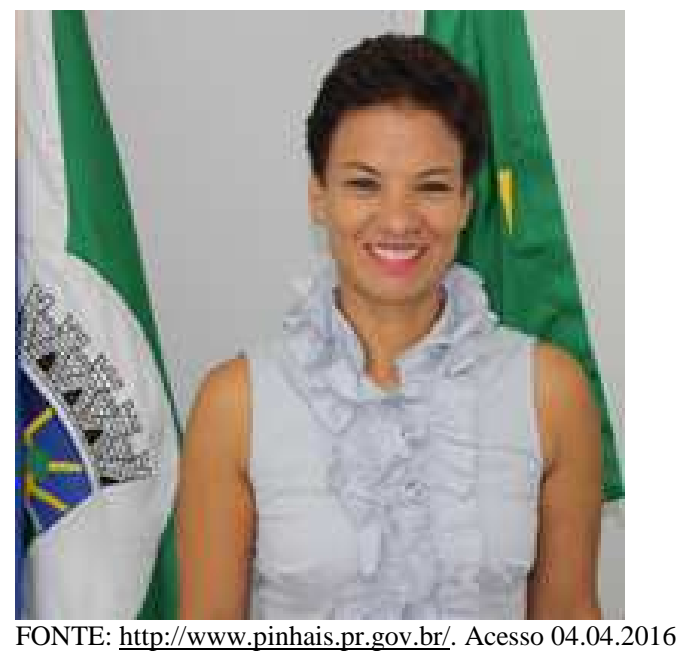

Marli nasceu em 7 abril 1965, na cidade de Goioerê, noroeste do Paraná. Chegou em Pinhais no início da década de 1980. Casou aos 17 anos. Tem dois filhos e dois netos. É formada em Gestão Pública. $^{24}$

Iniciou a carreira política nas eleições de 1996 quando foi eleita a primeira vereadora de Pinhais, para a $2^{\mathrm{a}}$ legislatura do município (1997-2000) aos 32 anos de idade pelo Partido Socialista Crstão/PSC. Nessa legislatura ocupou o cargo de $1^{\text {a }}$ Secretária da Câmara Municipal de Pinhais (CMP) no biênio 1997-1998. Na eleição seguinte, do ano de 2000, foi reeleita vereadora para a $3^{\mathrm{a}}$ legislatura do município (2001-2004) agora pelo PMDB. Nas eleições de 2004 se recandidata para o cargo de vereadora e é eleita para seu terceiro mandato consecutivo para a $4^{\text {a }}$ legislatura (20052008), ainda pelo PMDB e ocupa novamente o cargo de $1^{\text {a }}$ Secretária da CMP no biênio 2007-2008.

No ano de 2006 saiu candidata à deputada estadual pelo PV (Partido Verde) mas não foi eleita. Nas eleições de 2008 saiu como vice-prefeita na chapa com o Professor Luizão e foi eleita. Dessa vez sua filiação partidária era com o Partido Democrático Trabalhista/PDT.

Nas eleições de 2010 concorreu a uma vaga como deputada estadual, pelo PDT. Obteve 20.908 votos, mas não foi eleita ${ }^{25}$.

Nas eleições de 2012 se recandidata como vice-prefeita na chapa com o Professor Luizão e é reeleita. Ainda pelo PDT.

\footnotetext{
${ }^{24}$ Disponível em http://www.pinhais.pr.gov.br/FreeComponent2content172.shtml. Acesso 08.abril.2016

${ }^{25}$ Disponível em http://www.pinhais.pr.gov.br/News7content9784.shtml. Acesso 29.março.2016
} 
Nas eleições de 2014 concorre novamente a uma vaga como deputada estadual, pelo PDT. Obteve 26.317 votos mas não foi eleita, ficando com a primeira suplência do PDT $^{26}$.

\section{RITA DE CASSIA CRUZ ROMANIOW}

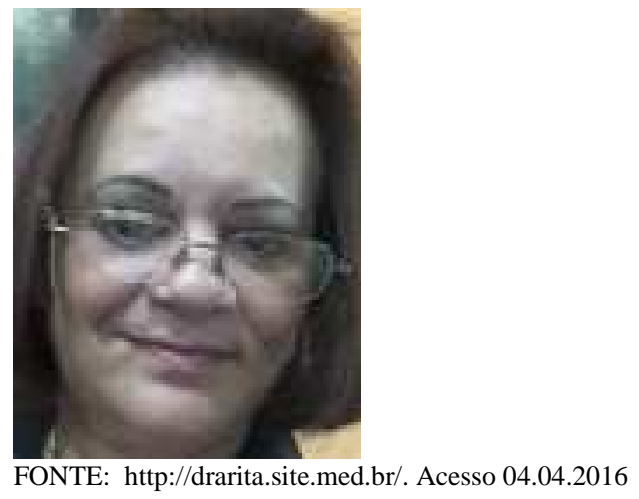

Rita nasceu em 09 de setembro de 1962 na cidade de Curitiba. Formada em Medicina, desde 1986, atua na área de obstetrícia e ginecologia. Casada com Paulo Romaniow ${ }^{27}$. Tem um filho ${ }^{28}$.

Iniciou a carreira política nas eleições de 2000 quando foi eleita vereadora de Pinhais, para a $3^{\text {a }}$ legislatura do município (2001-2004) aos 39 anos de idade pelo Partido Socialista Brasileiro/PSB. Nessa legislatura ocupou o cargo de 2a Secretária da CMP no biênio 2003-2004. Nas eleições seguinte, do ano de 2004, foi candidata à reeleição, agora pelo Democratas/DEM. Obteve 960 votos e ficou na suplência. ${ }^{29}$ Não voltou à vida política e hoje atua apenas como médica.

26 Ver Irregularidade de Sanson pode mexer na composição da Assembleia. Disponível em http://www.gazetadepalmeira.com.br/politica/irregularidade-na-candidatura-de-sanson-pode-mexer-na-composicao-daassembleia/. Acesso 08.abril.2016 e Ficha Politica disponível em http://www.fichapolitica.com.br/?fp=215766. Acesso 08.abril.2016

27 Paulo Romaniow faleceu em 24 de novembro de 2008. Disponível em http://www.bemparana.com.br/noticia/88978/mortos-em-24-de-novembro-de-2008 http://www.consultasocio.com/q/sa/rita-de-cassia-cruz-romaniow. Acesso 09.abril.2016.

28 Disponível em http://www.quadropolitico.com.br/DadosCandidato/2678260/Rita-De-Cassia-Cruz-Romaniow. Acesso 08.abril.2016

29 Disponível em http://www.radaroficial.com.br/d/17408059. Acesso 08.abril.2016 


\section{IVONE CARVALHO DOS SANTOS - IVONE DO PT}

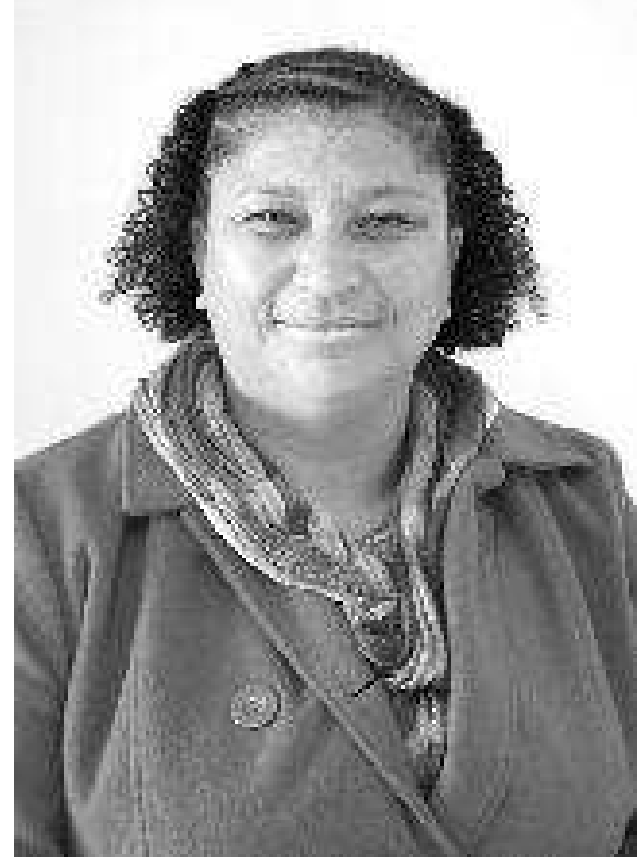

Fonte: http://eleicoes.uol.com.br/2012/candidatos. Acesso 29.fev.2016

Nasceu em Jaciara, estado de Mato Grosso, em 27 de abril de 1968, filha de Aluisio Rodrigues dos Santos e Marina Carvalho dos Santos. Chega em Piraquara em 1974, aos 7 anos de idade, após ter morado no interior de São Paulo e Norte do Paraná na cidade de Florestópolis, a 79 $\mathrm{Km}$ de Londrina. É solteira, possui o ensino médio completo e atuou na área de auxiliar administrativa antes de ser eleita vereadora.

Relata ter desde criança uma inclinação à liderança, rompendo barreiras exclusivamente masculina, jogando futebol na escola e negociando junto à direção uma agenda que incluísse os jogos femininos. Na igreja, foi uma das primeiras coroinhas de Piraquara, ainda com 9 anos, na Paróquia Nossa Senhora da Luz, antes Boa Esperança. Nessa igreja funcionava uma comunidade eclesial de base e junto com Padre Alberto desenvolve sua fé e política, com sua mãe ativa a solidariedade e com o pai a ação aos mais necessitados. ${ }^{30}$ Sempre envolvida na comunidade, participa junto com Luizão e Marcia Ferreira do grupo de jovens da paróquia.

Tendo como exemplo seu pai, um dos primeiros filiados do Partido dos Trabalhadores (PT), acompanha a constante luta pelo atendimento as carências da população, que entre outras demandas cria um clube de compras a preço de custo para a população. Filia-se ao PT em 1996. Auto define-

\footnotetext{
${ }^{30}$ Conforme entrevista concedida à Glória Estevinho em 29 de fevereiro de 2016.
} 
se como "uma pessoa incomodada com as injustiças sociais" e acredita que a "política é para melhorar a vida das pessoas" ${ }^{31}$. Atuando na CMP foi a primeira mulher presidente da casa.

Iniciou a carreira política nas eleições de 2004 quando foi eleita vereadora de Pinhais, para a $4^{\mathrm{a}}$ legislatura do município (2005-2008) aos 37 anos de idade pelo PT, com 1096 votos. Na eleição seguinte, do ano de 2008, foi reeleita vereadora pelo PT com 864 votos. Nessa legislatura ocupou o cargo de $1^{\text {a }}$ Secretária da CMP no biênio 2009-2010 e foi a primeira mulher Presidente da CMP no biênio 2011-2012 $2^{32}$.

Nas eleições de 2012 concorreu à reeleição, pelo PT. Obteve 998 votos, mas não foi reeleita. Atualmente está cursando a faculdade de Serviço Social e é Diretora de DEPSE (Departamento de Proteção Social Especial) na Prefeitura Municipal de Pinhais. ${ }^{33}$

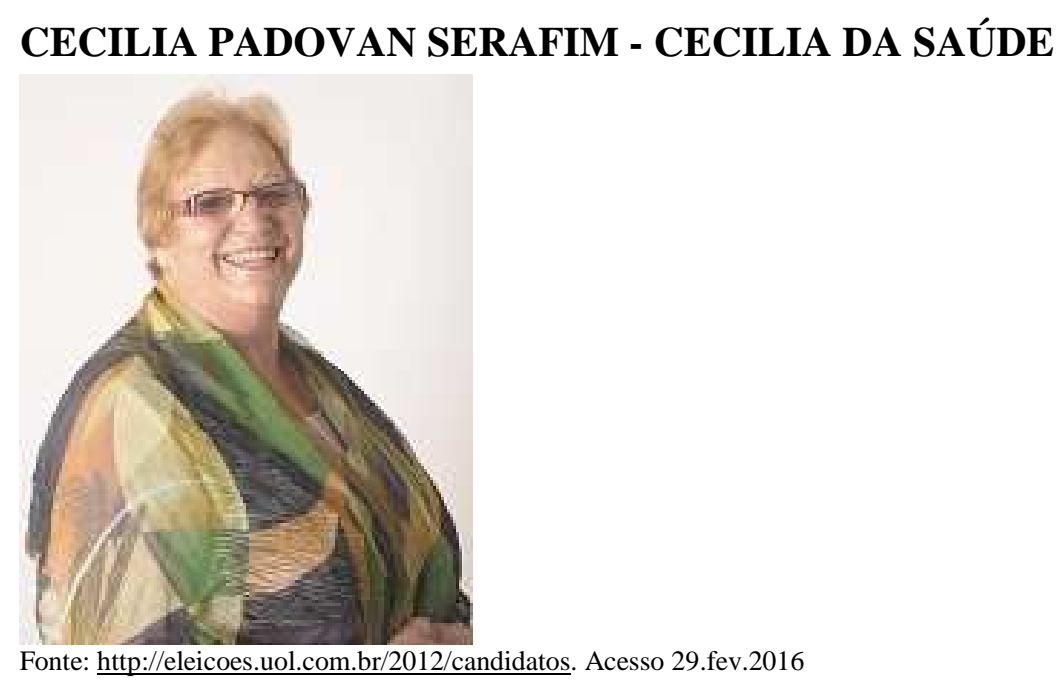

Nasceu em Ocauçu, estado de São Paulo em 29 de novembro de 1945. Aos 15 anos, em 1960, casa-se e vai morar em Barbosa Ferraz, estado do Paraná, onde dedica-se ao trabalho na lavoura, num sítio do sogro de seu irmão. É filha de Orlando Padovan e Inês Colombo Padovan, ambos trabalhadores rurais Em 1967 voltou para São Paulo, aonde concluiu o curso de

\footnotetext{
${ }^{31}$ Conforme entrevista concedida à Glória Estevinho em 29 de fevereiro de 2016.

${ }^{32}$ Dados coletados pessoalmente na Câmara Municipal de Pinhais.

${ }^{33}$ Disponível em http://www.pinhais.pr.gov.br/News7content9784.shtml. Acesso 29.março.2016
} 
Enfermagem, trabalhou no Hospital Oswaldo Cruz e no Hospital Nossa Senhora de Misericórdia em Osasco. No período em que morou em São Paulo, chegou a residir numa favela em Carapicuíba, onde cria os quatro filhos sozinha: João Everaldo Serafim, Júlio Everaldo Serafim, Jane Aparecida Serafim e Jackson Edenilson Serafim ${ }^{34}$. É avó de oito netos.

No ano de 1984 veio morar em Pinhais que na época ainda era Distrito da Cidade de Piraquara. Durante quatro anos trabalhou no Hospital e Maternidade de Pinhais. Em 1988 presta concurso para a área de saúde da Prefeitura de Piraquara. Em 1992, com a emancipação do município de Pinhais foi aprovada no primeiro concurso público realizado no município, aonde exerceu suas atividades na área da saúde de 1992 até 2012. Antes de ser candidata a vereadora atuou como coordenadora da Unidade de Saúde do Weissópolis por 21 anos.

Nas eleições de 2004 se candidata a vereadora, obtém 1126 votos e fica como suplente do DEM. Nas eleições seguinte, de 2008 concorre novamente ao cargo de vereadora, agora pelo PDT, obtem 1139 votos, mas não é eleita. Em 2012 é eleita vereadora pelo PDT, com 754 votos ${ }^{35}$. Sua plataforma eleitoral foi apresentar projetos voltados à família, saúde e idoso.

Considera-se uma mulher atuante na política com uma trajetória pessoal marcada pela coragem e determinação e por ter um trabalho muito gratificante. ${ }^{36}$

\section{MARCIA REGINA FERREIRA DA SILVA - MÁRCIA FERREIRA}

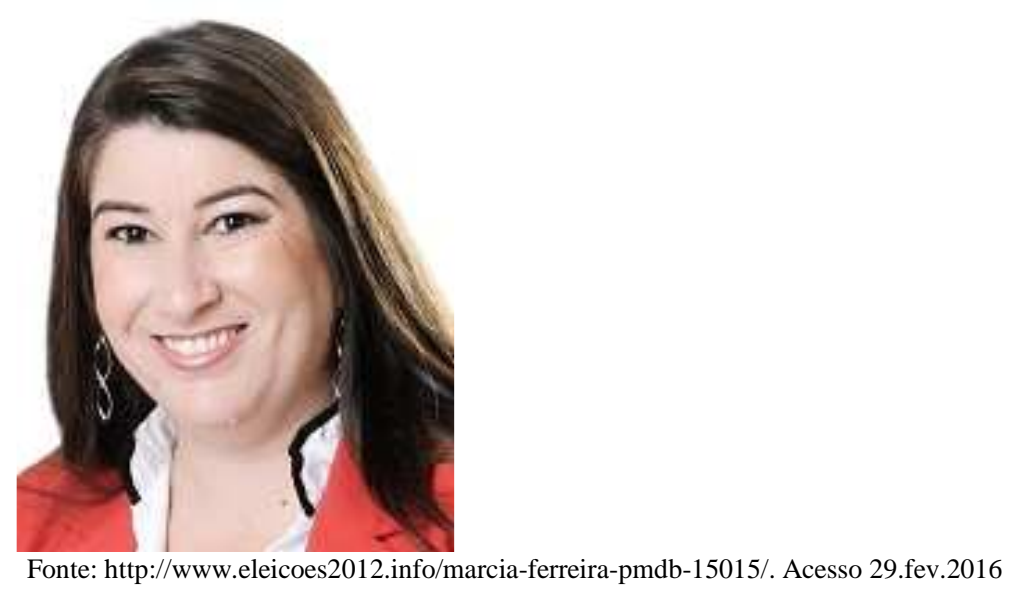

34 Falecido, vítima de acidente, foi cinegrafista do programa Carlos Alborghetti. Disponível em http://agoraparana.uol.com.br/sady/2689_maes.pdf. Acesso 29.fev.2016.

35 Disponível em http://www.quadropolitico.com.br/DadosCandidato/2311818/Cecilia-Padovan-Serafim. Acesso em 29.fev.2016.

${ }^{36}$ Conforme entrevista cedida à Glória Estevinho em outubro de 2015. 
Márcia Ferreira nasceu em 17 de julho de 1974 na cidade de Cianorte, região Norte do Paraná e veio morar em Pinhais aos nove meses de idade. É a filha mais nova de seis irmãos. Filha de José Ferreira, filiado ao Partido dos Trabalhadores, na década de 1980 e 1990 foi candidato a vereador pelo PT e um dos fundadores do partido em Pinhais. Participou da associação de moradores do bairro Maria Antonieta. Sua mãe, Terezinha Cristani era professora. Marcia sempre foi atuante com o grupo de jovens que praticava ações junto à comunidade sendo articuladora no movimento em prol de atitudes de conscientização referentes a AIDS, drogas, DST e na prevenção e cuidados com a saúde. Junto à comunidade promoveu o $1^{\circ}$ Festival de Música no município em 2009. Ainda estudante, foi à Cuba representando os estudantes de Pinhais no ano 2000. É casada, mãe de um filho, Socióloga formada pela Universidade Federal do Paraná e pós graduada em Política Nacional de Assistência Social pela PUC/PR. Desde muito jovem se engajou nos movimentos sociais, onde aprendeu sobre a importância da cidadania e desenvolveu seu interesse pela política. Entre 1988 a 1999 participou do Grupo Teatral Aquarela, do Grupo de Jovens da Paróquia São José Operário, do GEPEN - Grupo Ecológico pela Natureza, da Associação de Moradores do Bairro Maria Antonieta, foi presidenta da Juventude Socialista, dirigente da UNESPI - União dos Estudantes de Pinhais e da UPES - União Paranaense dos Estudantes Secundaristas. Entre 2000 a 2008 participou do DCE da UFPR, atuou também na Pastoral Familiar, foi vicepresidenta e coordenadora de projetos de alfabetização de jovens e adultos na Federação das Mulheres do Paraná e uma das fundadoras da UMP - União das Mulheres de Pinhais. Entre 2009 e 2012 foi Secretaria Municipal de Assistência Social e neste período implantou o SUAS (Sistema Único de Assistência Social) e formou uma grande equipe de trabalho que levou Pinhais a ser considerada pelo Ministério do Desenvolvimento Social como modelo em nível nacional em gestão de assistência social. Nesse período ocupou também outras funções relevantes, como a de Secretária Geral do CONGEMAS (Colegiado Nacional dos Gestores Municipais de Assistência Social) e Representante Regional do COGEMAS PR (Colegiado Estadual dos Gestores Municipais de Assistência Social). Fez parte da juventude Socialista do PDT, sendo a presidente mais jovem de partido político com 23 anos. Saiu do partido em 2004 por conta da entrada de Álvaro Dias.

Concorreu nas eleições de 2008 para vereadora, mas conseguiu apenas 609 votos e ficou como suplente do $\mathrm{PMDB}^{37}$. Nas eleições de 2012 foi eleita vereadora, com 982 votos, pelo PMDB e em seu primeiro mandato tem apresentado diversos projetos direcionados para área social, às

37 Disponível em http://www.quadropolitico.com.br/DadosCandidato/2311818/Cecilia-Padovan-Serafim. Acesso em 29.fev.2016. 
mulheres, ao desenvolvimento da infância e juventude e para o fortalecimento das famílias, além da construção de políticas públicas para fomentar a cultura, o esporte e melhorar os serviços de saúde e segurança pública. Márcia Ferreira é também a Primeira Secretária da Mesa Executiva da Câmara Municipal, titular da Comissão de Justiça e Redação, da Comissão de Segurança Pública e Vice Presidenta da Frente Parlamentar de Proteção Animal. Exerce ainda a Presidência do Diretório Estadual do PMDB Mulher do Paraná, é Diretora da Federação das Mulheres do Paraná e Conselheira Estadual do CONCIDADES-PR. Considera importante o papel da mulher na política e luta para atingir os $50 \%$ de participação, "não basta cumprir a legislação é preciso mudar a cultura política e incentivar a participação das mulheres" ${ }^{\text {38 }}$. O foco de seus projetos é voltado para a mulher empreendedora.

\section{MARIA JANEIDE DE SOUZA PIACENTINI - JANE CARTEIRA}

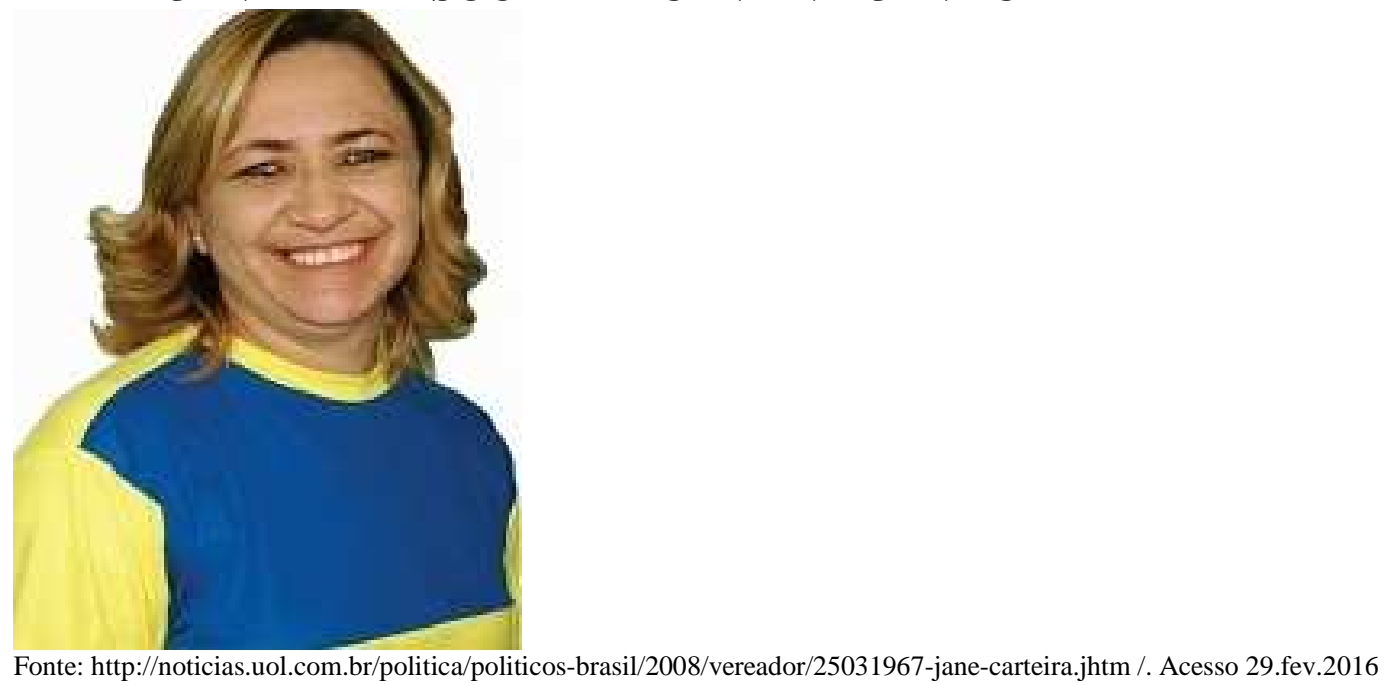

Maria Janeide de Souza Piacentini nasceu em 25 de março de 1967, em Sertânia, estado de Pernambuco. Filha de Isaías Galdino e Agda Batista, trabalhadores rurais. Casada com Gilberto Piacentini, metalúrgico, é mãe de três filhos: Alexandre Junior, carteiro em Piraquara, Gustavo Piacentini e Camila Piacentini. Tem uma neta. Há 26 anos mora em Pinhais, no Bairro Vargem Grande. Trabalhou como cabeleireira, costureira e vendedora. Aprovada em concurso público trabalhou por 12 anos nos Correios, passando a ser a primeira mulher Carteira do Município de Pinhais, onde ficou popularmente conhecida como "Jane Carteira". Nos Correios, atuava como

\footnotetext{
${ }^{38}$ Conforme entrevista concedida à Glória Estevinho em 29 de fevereiro de 2016.
} 
Delegada do Sindicato dos Carteiros. Jane foi à fundadora da feirinha de artesanato do município, que era realizada na Avenida Iraî39.

Concorreu para vereadora nas eleições de 2004, obteve 579 votos e ficou como suplente do PR. Nas eleições seguinte, de 2008 obteve 732 votos e não foi eleita. Foi eleita em 2012 com 1107 $\operatorname{votos}^{40}$

\section{ROSA MARIA DE JESUS COLOMBO}

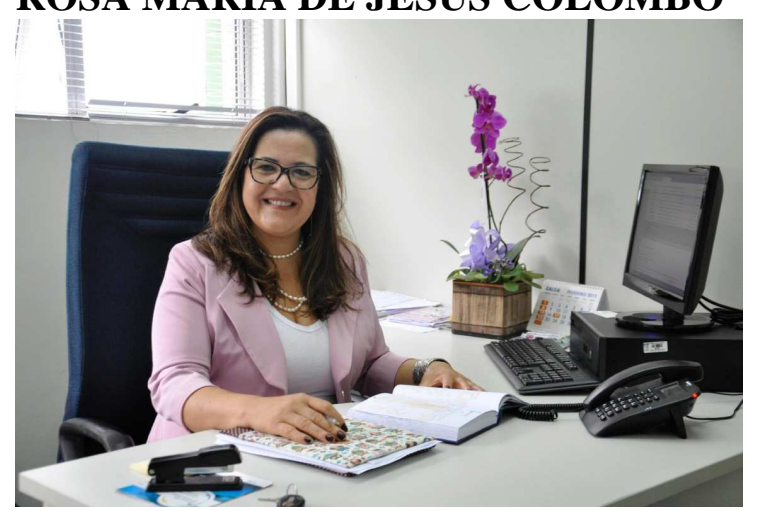

Fonte: http://www.eleicoes2014.com.br/professora-rosa-maria//. Acesso 29.fev.2016

Nasceu em Santa Fé, estado do Paraná, em 17 de setembro de 1965. Filha de José Manoel Nunes e Joviana Maria Nunes, ambos trabalhadores rurais. É a terceira filha do casal, de uma família de 5 irmãos. Casada com Jó Roel Colombo, é mãe de 4 filhas e tem dois netos. Fez seus estudos iniciais em escola pública e trabalhou como costureira e copeira, antes de graduar-se em Letras pela Faculdade de Jandaia do Sul (FAFIJAN). Também é pós-graduada em Metodologia de Ensino, pela Faculdade Espírita, e em Psicopedagogia pela UNICURITIBA. Fez uma especialização, pela UTFPR, em nível de mestrado, a qual deu origem ao artigo sobre a importância da leitura. Ainda cursou Magistério e Contabilidade, antes de ingressar no ensino superior. Professora de Português e Literatura, lecionou durante 31 anos, para o ensino fundamental e médio. Foi diretora, por dois mandatos, do maior colégio estadual de Pinhais, o Arnaldo Busato e do Colégio Estadual Humberto de Alencar Castelo Branco ${ }^{41}$.

Filiou-se ao PT em 2007. Iniciou a carreira política nas eleições de 2008 concorrendo ao cargo de vereadora pelo PT. Obteve 640 votos e ficou na suplência. Na primeira gestão do prefeito Luizão, Rosa Maria foi Secretária Municipal de Educação. ${ }^{42}$

\footnotetext{
${ }^{39}$ Conforme entrevista concedida à Glória Estevinho em 29 de fevereiro de 2016.

40 Disponível em http://www.quadropolitico.com.br/DadosCandidato/2301968/Maria-Janeide-De-Souza-Piacentini. Acesso em 29.fev.2016. Ver também https://apps.tre-pr.jus.br/files/resultados/20041003A75043.pdf.

${ }^{41}$ Conforme entrevista concedida à Glória Estevinho em novembro de 2015.
}

42 Disponível em http://www.panorama.com.br/index.php?option=com k2\&view=item\&id=9730:pinhais-novasecret\%C3\%A1ria-de-educa\%C3\%A7\%C3\%A3o-fala-de-prioridades\&Itemid=12. Acesso 29.fev.2016 
Nas eleições seguintes, de 2012, concorreu novamente ao cargo de vereadora, pelo PT e foi eleita para a $6^{\text {a }}$ legislatura (2013-2016). Em 2015 deixou o cargo de vereadora para assumir como Secretária Municipal de Administração da segunda gestão do prefeito Luizão. ${ }^{43}$ No seu lugar na CMP assume o suplente Carlos Pereira Borges da Rosa (Carlinhos do Eliza). Em abril de 2016 deixa o cargo de Secretária Municipal de Administração, no seu lugar assume o novo secretário José Martins dos Santos Silva e reassume a função de vereadora na CMP. ${ }^{44}$

43 Disponível em http://www.quadropolitico.com.br/DadosCandidato/1854427/Rosa-Maria-De-Jesus-Colombo e em http://noticiasparana.com/pinhais-rosa-maria-assume-secretaria-de-administracao/. Acesso em 29.fev.2016.

44

http://www.pinhais.pr.gov.br/aprefeitura/secretariaseorgaos/administracao/FreeComponent40content352.shtml. Acesso em 11.abril.2016. 


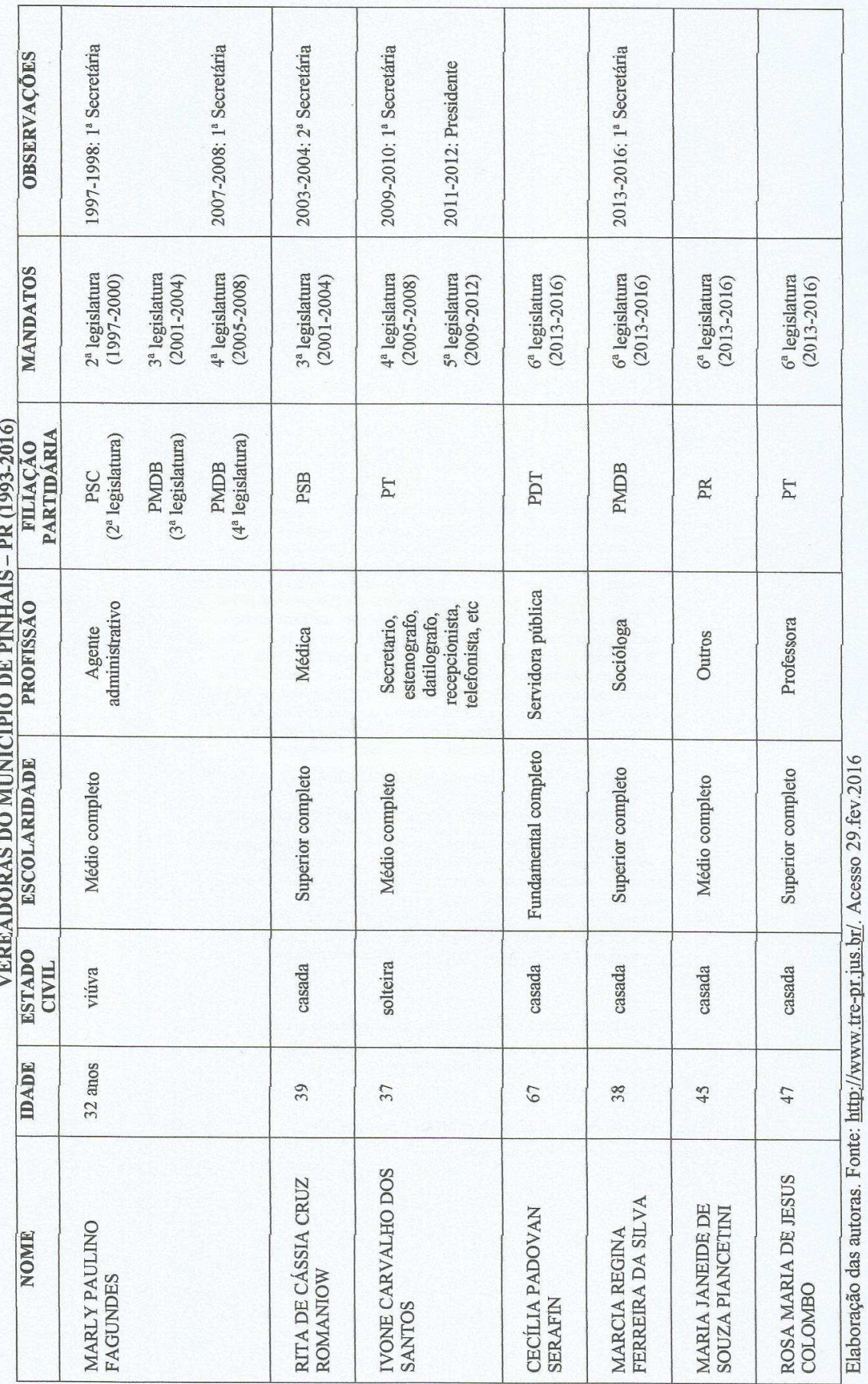




\section{CONSIDERAÇÕES FINAIS}

A compilação de dados apresentada nos permite observar que apesar de haver uma política pública institucionalizada através das ações afirmativas que preconizava o aumento da participação de mulheres no poder, ainda temos uma baixíssima representação feminina no legislativo municipal de Pinhais. Passados vinte e um anos da Lei 9100/95, observa-se que em Pinhais, somente agora, na

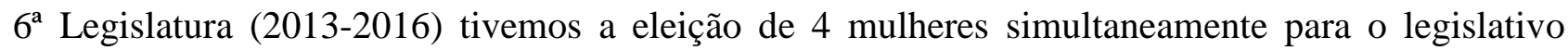
municipal ocupando 27\% das cadeiras. Nas legislaturas anteriores, na 1a (1993-1996) a eleição ocorreu sem cotas e não teve nenhuma mulher eleita. A partir da $2^{\mathrm{a}}$ legislatura (1997-200), a eleição já contava com a lei de cotas e temos a eleição da primeira vereadora de Pinhais e única nessa legislatura representando $6 \%$ das cadeiras disponíveis. Para a $3^{\mathrm{a}}(2001-2004)$ e $4^{\mathrm{a}}$ (2005-2008) legislaturas duas mulheres foram eleitas, em cada legislatura, fazendo um total de $12 \%$ de ocupação das cadeiras por mulheres. Na $5^{\text {a }}$ legislatura (2009-2012) somente uma vereadora foi eleita e voltase ao $6 \%$ de representação feminina na câmara municipal. Se compararmos desde a primeira legislatura, que teve uma mulher eleita, com a atual com quatro mulheres eleitas, percebemos que houve aumento de $20 \%$ no número de mulheres eleitas para a câmara municipal ${ }^{45}$.

A política de cotas não pode ser considerada o instrumento principal para a efetiva participação feminina no campo político institucionalizado. $\mathrm{O}$ fato de haver uma lei que institui cotas para a disputa dos cargos legislativos não garante as condições para as mulheres chegarem aos canais de poder de decisão, o que ocorre é a problematização da inclusão das mulheres no campo político. As candidatas eleitas para a Câmara Municipal de Pinhais já tinham um histórico de participação política ou de alguma causa que as trouxeram para o rol das elegíveis como o fato de serem médica, professora, agente de saúde, profissões que permitem acesso a um público diverso.

O trabalho destacou a atuação das mulheres no cargo legislativo, mas existem outros cargos que têm relevante poder de decisão, onde elas estão presentes e ainda carecem de estudos como os secretariados municipais, a vice prefeitura, etc. Também tem que se pensar que após terem chegado num dos campos do poder, quais são os capitais necessários para se jogar o jogo e aumentar as chances de continuarem nessa esfera de decisão.

Para a promoção da consciência política da mulher é necessário a educação política relacionada com os direitos e deveres cívicos, sobretudo o direito à participação. Os governos, parlamentos, partidos políticos, organizações não-governamentais e mídias podem todos contribuir para esse processo. Das sete vereadoras apresentadas, evidencia-se que existem semelhanças entre

\footnotetext{
${ }^{45}$ Ver quadro Candidatos à Câmara Municipal de Pinhais - PR/Eleições 2012 ao final do artigo. Nas eleições de 2012 dos 313 candidatos a vereador no município de Pinhais 94 eram mulheres e somente 4 foram eleitas.
} 
elas e que por um lado isso as fazem estar no campo do poder e que cada qual a seu modo utiliza os seus trunfos e capitais para se estabelecerem no campo político. Mas, é necessário continuar as pesquisas em torno do tema, pois o quadro exposto acima nos possibilita novas possibilidades de pesquisa e que não foram contempladas neste estudo por razões de tempo. Teria que se continuar pesquisando a trajetória política destas mesmas candidatas eleitas, com o intuito de perceber com mais precisão os movimentos delas no campo político, se permanecem na estrutura e quais as estratégias utilizadas para que isso ocorra. Este artigo, não teve a pretensão de esgotar os resultados, mas contribuir apontando possibilidades para apreensão das relações que se estabelecem socialmente.

\section{REFERÊNCIAS}

OLIVEIRA, Ricardo Costa de (2012). Na teia do nepotismo: sociologia política das relações de parentesco e poder político no Paraná e no Brasil. Curitiba: Editora Insight.

OLIVEIRA, Ricardo Costa de (2001). O silêncio dos vencedores: genealogia, classe dominante e Estado do Paraná. Curitiba: Editora Moinho do Verbo.

SCHMIDT, Maria Auxiliadora e GARCIA, Tânia Maria F. Braga (2000). Recriando histórias de Pinhais. Curitiba: TMFBraga Garcia.

SILVA, Márcia Regina Ferreira da (2008). A emancipação política do município de Pinhais: entre a identidade territorial e a articulação política das lideranças. Curitiba: Monografia de Graduação em Ciências Sociais.

SILVA, Rodolfo dos Santos (org) (2010). Identidade Pinhais. Curitiba: Top Graf.

TOMIO, Fabrício Ricardo de Lima (2002). A criação de municípios após a constituição de 1988. IN: Revista Brasileira de Ciências Sociais, v. 17, n. 48, fev. 2002. Disponível em: Acesso em: 24.março.2016.

XAVIER, Aarão de Paula (2000). Nos trilhos do tempo: história e memória de Pinhais. Pinhais: Prefeitura Municipal.

\section{SITES CONSULTADOS}

Justiça Eleitoral. Disponível em https://apps.tre-pr.jus.br/files/resultados/19921003A74357.pdf. Acesso em 29.fev.2016. 
Pinhais: candidatos à vereador nas eleições de 2012. Disponível http://www.eleicoes2012.info/candidatos-vereador-pinhais-pr/. Acesso em 25.março.2016.

Projeto Inicial de Emancipação de Pinhais. http://www.pinhais.pr.gov.br/projeto20anos/FreeComponent329content3281.shtml. Acesso em 25.março.2016.

Quadro político: candidatos do município de Pinhais. Disponível em http://www.quadropolitico.com.br/DadosMunicipio/4178/Pinhais/2444747. Acesso em 29.fev.2016.

Quadro político: candidatos do município de Pinhais. Disponível em http://www.quadropolitico.com.br/DadosCandidato/2094147/Marly-Paulino-Fagundes. Acesso em 29.fev.2016.

Quadro político: candidatos do município de Pinhais Disponível emhttp://www.quadropolitico.com.br/DadosCandidato/1854427/Rosa-Maria-De-Jesus-Colombo. Acesso em 29.fev.2016.

\title{
LEGISLATIVE POWER AND WOMEN IN PINHAIS
}

\section{(1993-2016)}

\begin{abstract}
This article aims to analyze the political participation of women in the Municipality of Pinhais, the metropolitan region of Curitiba / PR between the years 1993 to 2016. For this purpose, a database of candidates elected was built and, with it, Could provide a record of women's participation in municipal elections, analyze the profile of councilors from social and economic dimensions, such as age, marital status, education, occupation and political affiliation. The results mark a very low female participation compared to the male presence. Despite certain openness and incentive for greater participation of women in political party life, as established by the quota law, this share falls far short of their populations, as shown by the data on women's participation in local legislative power Pinhais.
\end{abstract}

Key-words: Women in politics. Policy and gender. Hall Pinhais. 


\begin{tabular}{|c|c|c|c|c|}
\hline \multicolumn{5}{|c|}{ Candidatos à Câmara Municipal de Pinhais - PR/Eleições 2012} \\
\hline $\begin{array}{l}\text { PARTIDO } \\
\text { POLÍTICO }\end{array}$ & $\begin{array}{c}\text { TOTAL DE } \\
\text { CANDIDATOS }\end{array}$ & CANDIDATAS & NOME CANDIDATA & $\begin{array}{l}\text { TOTAL DE } \\
\text { VOTOS }\end{array}$ \\
\hline \multirow[t]{6}{*}{ PT } & 27 & 6 & Ana Paula Bruinje & 46 \\
\hline & & & Branca & 16 \\
\hline & & & Dra. Jamile & 144 \\
\hline & & & Ivone do PT & 998 \\
\hline & & & Professora Tereza & 189 \\
\hline & & & Professora Maria Rosa & 1437 \\
\hline PTB & 2 & 1 & Rafa & 1 \\
\hline \multirow[t]{9}{*}{ PMDB } & 26 & 9 & Deise Rosa & 231 \\
\hline & & & Dra. Denise & 41 \\
\hline & & & Dra. Eliane & 164 \\
\hline & & & Ivana & 107 \\
\hline & & & Jovita Viana & 133 \\
\hline & & & Juçara & 423 \\
\hline & & & Marcia Ferreira & 982 \\
\hline & & & Professora Silvina & 88 \\
\hline & & & Wilma da União & 315 \\
\hline PSL & 9 & 1 & Dra. Marta Brito & 25 \\
\hline PTN & 1 & zero & & \\
\hline \multirow[t]{9}{*}{ PSC } & 28 & 9 & Ana Paula & 4 \\
\hline & & & Dazilda & 3 \\
\hline & & & Fatima & 107 \\
\hline & & & Ilma & 2 \\
\hline & & & Izaura & 2 \\
\hline & & & Karla & 37 \\
\hline & & & Lindete & 341 \\
\hline & & & Sirlene & 1 \\
\hline & & & Zelia & 92 \\
\hline PRB & 3 & 1 & Cleunice & 2 \\
\hline \multirow[t]{7}{*}{ PP } & 21 & 7 & Celia & 32 \\
\hline & & & Cicera & 173 \\
\hline & & & Dione Furquim & 50 \\
\hline & & & Pastora Simone & 9 \\
\hline & & & Professora Mara & 3 \\
\hline & & & Professora Vilma & 36 \\
\hline & & & Salete Costureira & 104 \\
\hline \multirow[t]{7}{*}{ PDT } & 29 & 7 & Bete Ferreira & 39 \\
\hline & & & Cecília Padovam da Saúde & 754 \\
\hline & & & Dirce Fogaça & 197 \\
\hline & & & Helena Cavip & 53 \\
\hline & & & Linda & 183 \\
\hline & & & Natalia Macedo & 342 \\
\hline & & & Rose do Porto & 387 \\
\hline \multirow[t]{3}{*}{ PSDC } & 13 & 3 & Dora do Gas & 1 \\
\hline & & & Teresinha do Forum & 53 \\
\hline & & & Zelair Iza Poetisa & 23 \\
\hline PRTB & 1 & Zero & & \\
\hline \multirow[t]{3}{*}{ PHS } & 6 & 3 & Cleusi & 49 \\
\hline & & & Maria Rossi & 28 \\
\hline & & & Rosilene & 48 \\
\hline \multirow[t]{2}{*}{ PMN } & 3 & 2 & Alice Colombo & 1 \\
\hline & & & Lourdes da Santa Rita & 1 \\
\hline PTC & 1 & zero & & \\
\hline PC do B & 1 & zero & & \\
\hline
\end{tabular}




\begin{tabular}{|c|c|c|c|c|}
\hline \multirow[t]{10}{*}{ PSB } & 32 & 10 & Analice & 43 \\
\hline & & & Cida da Pamonha & 105 \\
\hline & & & Debora de Souza & 3 \\
\hline & & & Dinalva Santana & 10 \\
\hline & & & Marcia Oliveira & 79 \\
\hline & & & Marcioxas & 27 \\
\hline & & & Maria Ribeiro & 26 \\
\hline & & & Michelli da Creche & 186 \\
\hline & & & Nive Voluntária Social & 177 \\
\hline & & & Polaca do Music Bar & 18 \\
\hline \multirow[t]{9}{*}{$\mathrm{PV}$} & 18 & 9 & Dona Mada & 1 \\
\hline & & & Eliane Scheffer & 1 \\
\hline & & & Jenifer & 13 \\
\hline & & & Jussara Elisa & 208 \\
\hline & & & Lia & 114 \\
\hline & & & Nete & 2 \\
\hline & & & Professora Neusa Wagatuma & 1 \\
\hline & & & Professora Raquel & 116 \\
\hline & & & Vanessa & 2 \\
\hline \multirow[t]{3}{*}{ PRP } & 12 & 3 & Cheron & 8 \\
\hline & & & Janaina & 3 \\
\hline & & & Jaqueline Manicure & 3 \\
\hline \multirow[t]{6}{*}{ PSDB } & 20 & 6 & Angela & 49 \\
\hline & & & Celia Regina & 1 \\
\hline & & & Eliziane & 1 \\
\hline & & & Ivone & 1 \\
\hline & & & Neusinha & 3 \\
\hline & & & Professora Dirce & 1 \\
\hline \multirow[t]{3}{*}{ PSD } & 13 & 3 & Adriane & 1 \\
\hline & & & Eva Lopes & 1 \\
\hline & & & Keila & 1 \\
\hline \multirow[t]{8}{*}{$\mathrm{PR}$} & 20 & 8 & Cintya & 1 \\
\hline & & & Dona Lica & 1 \\
\hline & & & Elaine Cobradora & 71 \\
\hline & & & Jane Carteira & 1107 \\
\hline & & & Paloma Yara & 37 \\
\hline & & & Railda & 113 \\
\hline & & & Sonia do Boni & 36 \\
\hline & & & Tia Lourdes do Yakult & 99 \\
\hline \multirow[t]{6}{*}{ PPS } & 26 & 6 & Marcia de Fatima & 70 \\
\hline & & & Nina & 40 \\
\hline & & & Rossy & 90 \\
\hline & & & Sol Pires & 102 \\
\hline & & & Vaneli & 213 \\
\hline & & & Zica & 7 \\
\hline DEM & 1 & zero & & \\
\hline
\end{tabular}

Elaboração das autoras. Fonte: http://www.tre-pr.jus.br/.. Acesso 29.fev.2016 